\title{
INVESTIGATION OF THE DEFORMABILITY OF ALUMINIUM-COPPER CASTING ALLOYS
}

\author{
Grzegorz Winiarski', Anna Dziubińska', Krzysztof Majerski', \\ Michał Szucki², Krzysztof Drozdowski ${ }^{3}$ \\ 1 Lublin University of Technolgy, ul. Nadbystrzycka 36, 20-618 Lublin, Poland, e-mail: g.winiarski@pollub.pl, \\ a.dziubinska@pollub.pl,k.majerski@pollub.pl \\ 2 AGH University of Science and Technology, al. Mickiewicza 30, 30-059 Kraków, Poland, e-mail: mszucki@agh. \\ edu.pl \\ 3 Plastic Forming Plant (Zakład Obróbki Plastycznej Sp. z o.o.), ul. Kuźnicza 13, 21-045 Świdnik k/Lublina, e-mail: \\ krzysztof_drozdowski@kuznia-zop.pl
}

Received: 2018.07.12

Accepted: 2018.08.05

Published: 2018.09.01

\begin{abstract}
The paper presents the results of a numerical analysis and experimental tests investigating the deformability of castings made of two aluminium alloys: EN AW-2017A and EN AW-2024. Test specimens were produced by two casting methods: sand casting and permanent mould casting. The castings were first subjected to homogenizing annealing; afterwards, they were shaped into cylindrical specimens for an upsetting test. This test was conducted on a hydraulic press in the temperature range of 420$500^{\circ} \mathrm{C}$. Visual inspection of the specimens and examination of their microstructure were performed. Hardness of selected specimens was also measured. The study led to determination of the effect of the mould type on the deformability of the castings and the hardness of forgings obtained from these casting. Obtained results also became a basis for determining the forging temperature ranges for casting preforms made of the investigated aluminium alloys.
\end{abstract}

Keywords: aluminium alloy, metal forming, upsetting test, qualitative research.

\section{INTRODUCTION}

A wide variety of production technologies are used for producing parts for machines and devices. The most popular are machining, metal working, casting and polymer processing. The choice of a suitable technique depends on many factors, such as material grade, product geometry and manufacturing accuracy, production volume, manufacturing performance, product strength properties and manufacturing costs. In many cases, the manufacturing of a part requires the use of different techniques, e.g. casting and finishing treatment. The implementation of various techniques into a manufacturing cycle results in a shorter production time, reduced manufacturing costs, and obtaining products with required shape, size and quality. For this reason, in recent years, one can observe a rapid development of a manufacturing technique that combines casting and forging methods. This production method consists in forging of a preform produced by casting. As a result, it is possible to produce parts with complex shapes and/or made of materials with limited deformability. The use of metal working improves the mechanical properties of a preform produced by casting and reduces structural defects produced in the casting process.

The casting/forging process depends on many factors. Zhang et al. [1] investigated an integrated casting and forging process for producing an aluminium automobile wheel, analysing, among others, the temperature of the dies, the time between casting and forging, forging force and metal flow kinematics. The results showed that the microstructure in the deformed areas is 
fine-grained and more homogeneous than in the non-deformed ones. In addition, the mechanical properties of the product are higher than those of the casting. Płonka et al. [2] studied EN AW-6082 alloy and demonstrated that the use of ingots in a die forging process produces forgings with more desired micro- and macrostructures and higher mechanical properties, when compared to those of forgings made from extruded rods. Kim et al. [3] investigated the manufacturing of tie-rod ends with the casting/forging process in order to determine a relationship between the shape of the casting preform and the forging. The tests demonstrated that incorrect shape of the billet leads to the occurrence of forging defects such as underfill or overlap. Wang et al. [4] studied the casting/ forging process for producing a flange and determined technological parameters of the casting and forging processes for aluminium alloy 5083 . Taking advantage of standard tests for investigating properties of materials, they determined the optimal forging temperature and strain rate as well as the effect of strain on the mechanical properties and geometry of the casting preform. The results obtained for the tested alloy enabled correct implementation of the forging process for producing a large flange. Zhou et al. [5] studied an automobile brake bracket to determine, among others, the effect of casting speed, forging stresses and mechanical properties of products. The tests showed that the above-mentioned technological parameters of the process have a significant impact on the structure and properties of the tested aluminium alloy A356.

A survey of the state-of-the-art in the problem area has revealed that the application of the forging process for the treatment of casting preforms

a)

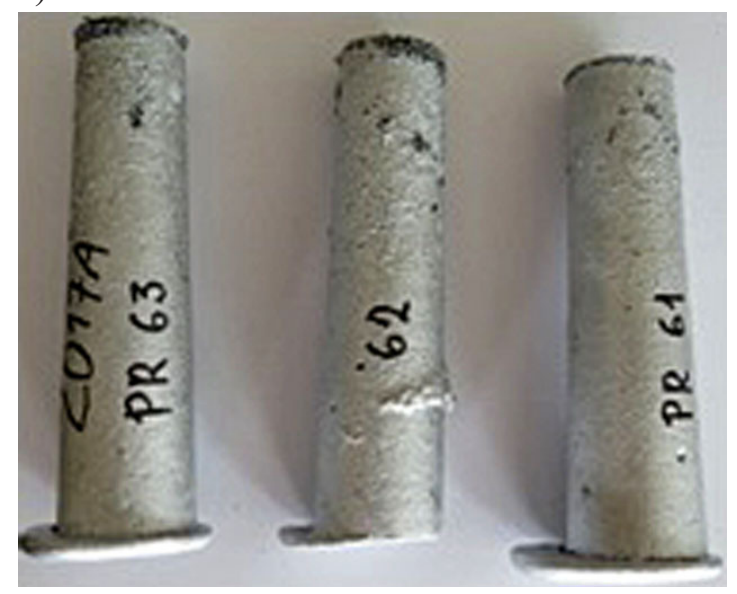

is justified in manufacturing processes. Consequently, research in this area should be continued. This paper presents the results of a study investigating the deformability of castings made of EN AW-2017A and EN AW-2024 alloys. Test specimens were produced by two casting methods: sand casting and permanent mould casting. The tests were carried out for different workpiece temperatures. Obtained results led to determination of the deformability range for castings made of aluminium-copper alloys.

\section{METHODS}

The assessment of deformability of the castings made of EN AW-2017A and EN AW-2024 alloys was performed via upsetting testing carried out in accordance with PN-H-04411 [6]. Test specimens were produced by two casting methods: permanent mould casting and sand casting. The castings obtained in this way were subjected to homogenizing annealing at $495^{\circ} \mathrm{C}$ for 24 hours. The castings were then peeled and shaped into cylindrical specimens (Fig. 1). The upsetting test was carried out on a Narges MX 700 hydraulic press provided with a specially designed open die forging tool with two flat anvils. The specimens of the studied types of aluminium alloys were subjected to hot upsetting in a temperature ranging from 420 to $500{ }^{\circ} \mathrm{C}$, changed every $20^{\circ} \mathrm{C}[7,8]$. In the upsetting test, the tools in direct contact with the workpiece were heated to a temperature of $250^{\circ} \mathrm{C}$.

Effective stresses, strains and the normalized Cockcroft-Latham ductile fracture criterion were determined in numerical simulations performed by the finite element method. The simulations were made in Deform-3D. This software has been effectively used in previous studies to investigate metal forming processes [9-11]. The simulations were performed on material models of aluminium alloys obtained from the software's material database. The temperature of the work-

b)

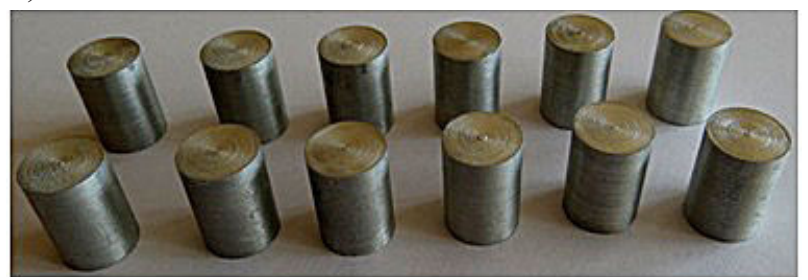

Fig. 1. Examples of: a) sand castings made of EN AW-2017A and b) cylindrical specimens made of these castings 
piece and the tools were the same as those applied in the experimental tests; likewise, the speed of the upper anvil was set equal to $8 \mathrm{~mm} / \mathrm{s}$ as in the experiments. The workpiece-tool contact was described with a constant friction model and the friction factor $m=0.72$ [12]. The thermal conductivity between the workpiece and the tools was set equal to $15 \mathrm{~kW} / \mathrm{m}^{2} \mathrm{~K}$, whereas that between the workpiece and the environment to $0.2 \mathrm{~kW} / \mathrm{m}^{2} \mathrm{~K}$ [13]. The time between workpiece removal from the furnace and placing it between the tools was set equal to $2 \mathrm{~s}$. The discretization of the billet was performed with approx. 150,000 four-node tetragonal elements.

\section{RESULTS AND DISCUSSION}

Specimens of aluminium alloys EN AW2017A and EN AW-2024 obtained during the upsetting test are described in Tables 1 and 2, respectively. On naked-eye visual inspection of the products obtained from upsetting, it can be observed that both the mould type and forging temperature have a key impact on the deformability of the analysed aluminium alloy castings. The sandmould castings made of EN AW-2017A alloy that were upset in the temperature range of 420-480 ${ }^{\circ} \mathrm{C}$ show the presence of cracks on their lateral surface. Only the specimens upset at $500^{\circ} \mathrm{C}$ are

Table 1. Specimens of aluminium alloy EN AW-2017A after upsetting in different temperatures

\begin{tabular}{|c|c|c|}
\hline \multicolumn{3}{|c|}{ Aluminium alloy EN AW-2017A } \\
\hline Upsetting Temperature $\left[{ }^{\circ} \mathrm{C}\right]$ & Sand Mould & Steel Permanent Mould \\
\hline \multicolumn{3}{|l|}{420} \\
\hline \multicolumn{3}{|l|}{440} \\
\hline \multicolumn{3}{|l|}{460} \\
\hline \multicolumn{3}{|l|}{480} \\
\hline \multicolumn{3}{|l|}{500} \\
\hline & & \\
\hline
\end{tabular}


Table 2. Specimens of aluminium alloy EN AW-2024 after upsetting in different temperatures

\begin{tabular}{|c|c|c|}
\hline \multicolumn{3}{|c|}{ Aluminium alloy EN AW-2024 } \\
\hline Upsetting Temperature $\left[{ }^{\circ} \mathrm{C}\right]$ & Sand Mould & Steel Permanent Mould \\
\hline \multicolumn{3}{|l|}{420} \\
\hline \multicolumn{3}{|l|}{440} \\
\hline \multicolumn{3}{|l|}{460} \\
\hline \multicolumn{3}{|l|}{480} \\
\hline \multicolumn{3}{|l|}{500} \\
\hline & & \\
\hline
\end{tabular}

free from the material cohesion loss. As for the permanent-mould castings, cracking only occurs in the specimens upset at $500^{\circ} \mathrm{C}$, but this defect does not occur in the forging temperature range of $420-480^{\circ} \mathrm{C}$. The inspection of EN AW-2024 alloy sand-mould castings reveals that defects occur in the specimens upset at $420-460^{\circ} \mathrm{C}$. The steel permanent-mould castings made of this alloy show no presence of material cohesion loss during forging at any of the tested temperatures. Therefore, based on the visual inspection of the specimens, it can be stated that the forging temperatures that ensure defect-free products are: $500^{\circ} \mathrm{C}$ and 420 $480^{\circ} \mathrm{C}$ for EN AW-2017A alloy sand-mould and permanent-mould castings, respectively; and $480-500^{\circ} \mathrm{C}$ and $420-500^{\circ} \mathrm{C}$ for $\mathrm{EN} \mathrm{AW}-2024$ alloy sand-mould and permanent-mould castings, respectively.

All examined specimens have only one defect, i.e. cracks on their lateral surface. Given the numerical results, this area is the most prone to material cohesion loss, as indicated by the results of 


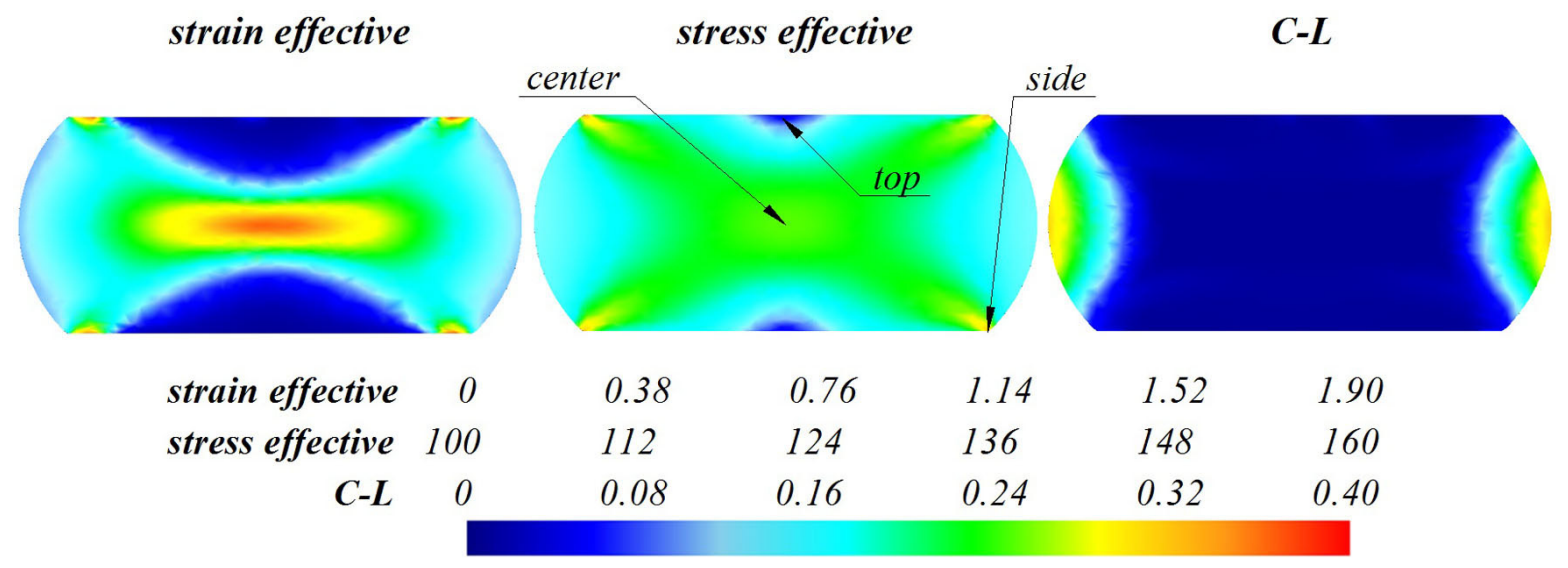

Fig. 2. Distribution of effective strains, effective stresses and the normalized Cockcroft-Latham ductile fracture criterion, obtained for EN AW-2017A specimens deformed at $500^{\circ} \mathrm{C}$.

the normalized Cracker-Latham ductile fracture criterion shown in Figure 2. In the zones where cracking has occurred, the criterion is about 0.4 , but the effective stress is about $120 \mathrm{MPa}$.

Microstructure examination was performed for the temperature ranges selected on the basis of the upsetting test. Microstructure images of castings, castings after homogenizing annealing, and castings after homogenizing annealing and upsetting were captured. The microstructure of the deformed specimens was examined in three zones located in the axial cross-section of the specimen, i.e. on the top, in the centre, and on the side of the specimen. These zones are marked in Figure 2 and have different effective strains: $0,1.9$ and 1 approx. Selected structures of the tested alloys are given in Tables 3 and 4.

The microstructure of the 2017A alloy sandmould casting consists of globular grains of various sizes. The alloy's matrix is phase $\alpha(\mathrm{Al})$, on the boundaries of which there are intermetallic phases containing aluminium, copper and silicon. After homogenization, some precipitates on the grain boundaries dissolve, and the segregation within the alloy is reduced. Nevertheless, there are still some precipitates that do not dissolve. After homogenization, in the grain area one can notice fine disperse precipitates formed due to partial supersaturation of the alloy. The grain size does not increase during the process. The upset specimens have non-homogeneous grains on the top, band structure in the centre, while their side may show the presence of cracks on the grain boundaries. The degree of grain deformation in the centre of the upset specimens decreases with increasing the forging temperature - this is particularly visible after forging at $500^{\circ} \mathrm{C}$.
In the microstructure of the EN AW-2017A alloy permanent-mould casting after homogenizing annealing one can observe significant homogenisation of the material. Eutectic precipitates dissolve completely. Other intermetallic phase precipitates are evenly distributed. Small precipitates that are evenly distributed in the grain area can also observed. The microstructure of the upset specimens is similar to that of the sand-mould castings - the higher the forging temperature is, the less banded the structure is and the more recrystallized the grain becomes. Grains are regular in the top part of the specimen, while in its centre - they are significantly deformed.

As for the EN AW-2024 alloy sand-mould specimen, its microstructure is initially globular (equiaxed grains). It consists of matrix $\alpha(\mathrm{Al})$ and intermetallic phase precipitates on the grain boundaries. These precipitates are dendritic eutectics of $\mathrm{A} 12 \mathrm{Cu}$ and $\mathrm{A} 12 \mathrm{CuMg}$. After homogenization, most eutectics are dissolved, and the fraction of large precipitations of intermetallic phases is significantly reduced. One can notice fine precipitates of intermetallic phases formed as a result of supersaturation of the alloy (during cooling after homogenization). Thorough examination of the fine precipitates has revealed the presence of Widmanstätten patterns formed during slow cooling. In the top area of the specimens upset at $420^{\circ} \mathrm{C}$ and $460^{\circ} \mathrm{C}$ one can observe the dominance of globular grains, their size being similar to that of the specimens after homogenization, and small strains. In the centre of the specimens one can observe strongly flattened grains that indicate the direction of metal flow. On the sides of some specimens one can notice cracks along the alloy grain boundaries. In the specimen upset at $500^{\circ} \mathrm{C}$, the grain size on the top 
Table. 3. Microstructure of EN AW-2017A alloy

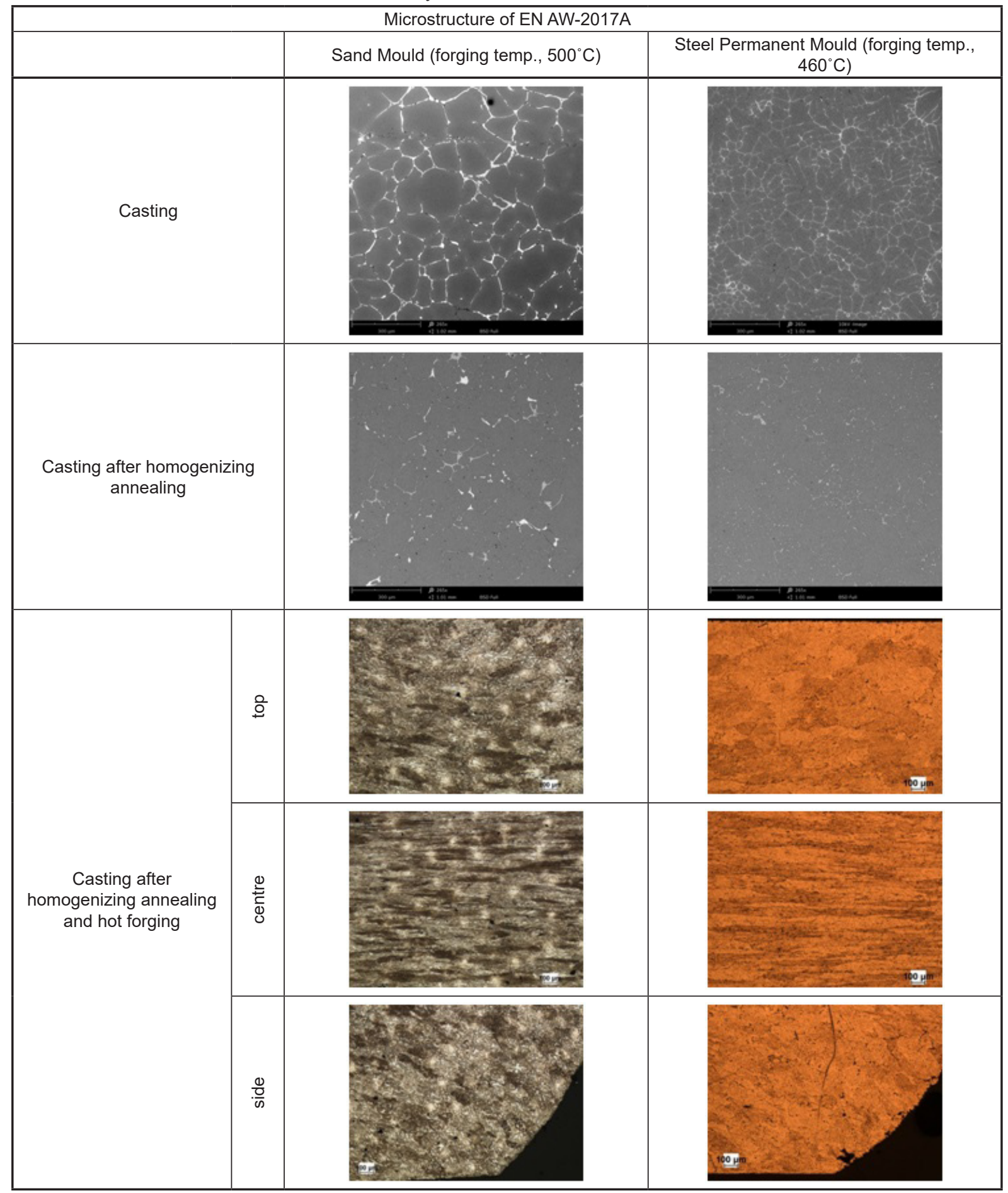

is slightly larger. In the centre of the upset specimen, the visible grains are clearly less flattened, which is caused by dynamic recrystallization.

On the basis of visual assessment of the specimens and examination of their microstructure, it has been found that the most favourable forging temperatures for alloys EN AW 2017A and 2024 are 500 and $460^{\circ} \mathrm{C}$ for sand-mould and permanent-mould castings, respectively.
The specimens upset in the above temperatures were examined for hardness, and obtained results together with the hardness of the castings are given in Figure 3. It can be observed that in all cases, due to the metal working processes, the hardness increases compared to the hardness of the castings after homogenizing annealing. The highest increase in hardness of $68.8 \%$ (from 76 to 128.3 HV10) can be observed for the sand-mould 
Table. 4. Microstructure of EN AW-2024 alloy

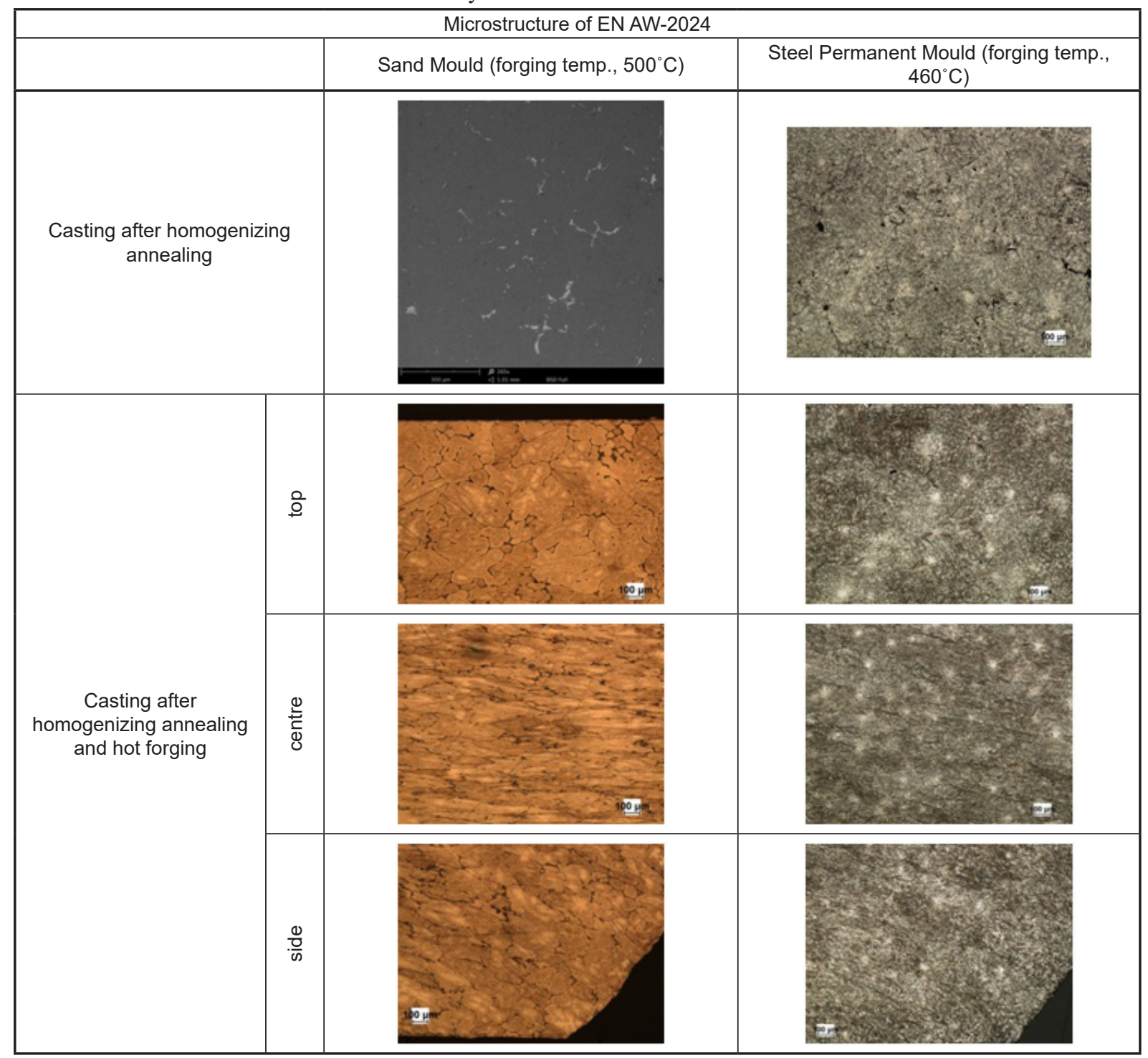

castings made of EN AW-2017A alloy, while the smallest $-3.7 \%$ for the EN AW-2024 alloy permanent-mould castings. For both tested aluminium alloys, the increase in hardness after forging (in comparison to the casting hardness after homogenization) is greater for sand-mould castings than for permanent-mould castings. For the EN AW-2017A alloy the hardness increase after forging is 68.8 and $27.7 \%$ and for the EN AW-2024 alloy - it is 28.5 and $3.7 \%$ for sand-mould and permanent-mould castings, respectively.

\section{CONCLUSIONS}

Based on obtained results, the following conclusions can be formulated:
1. The upsetting test is an effective method for assessing the deformability of cast aluminium alloys,

2. Selection of the mould type (sand or steel permanent moulds) has a crucial effect on casting deformability,

3. Visual assessment of the test specimens and examination of their microstructures have demonstrated that the recommended forging temperatures for en aw-2017a and en aw-2024 alloys are 500 and $460^{\circ} \mathrm{c}$ for sand mould castings and steel permanent mould castings, respectively; for both tested alloys, the forging temperature of sand mould castings is higher than that of steel permanent mould castings,

4. The upsetting test has revealed that cracking may occur when deforming en aw-2017a and 
castings

castings after homogenizing annealing castings after homogenizing annealing and upsetting

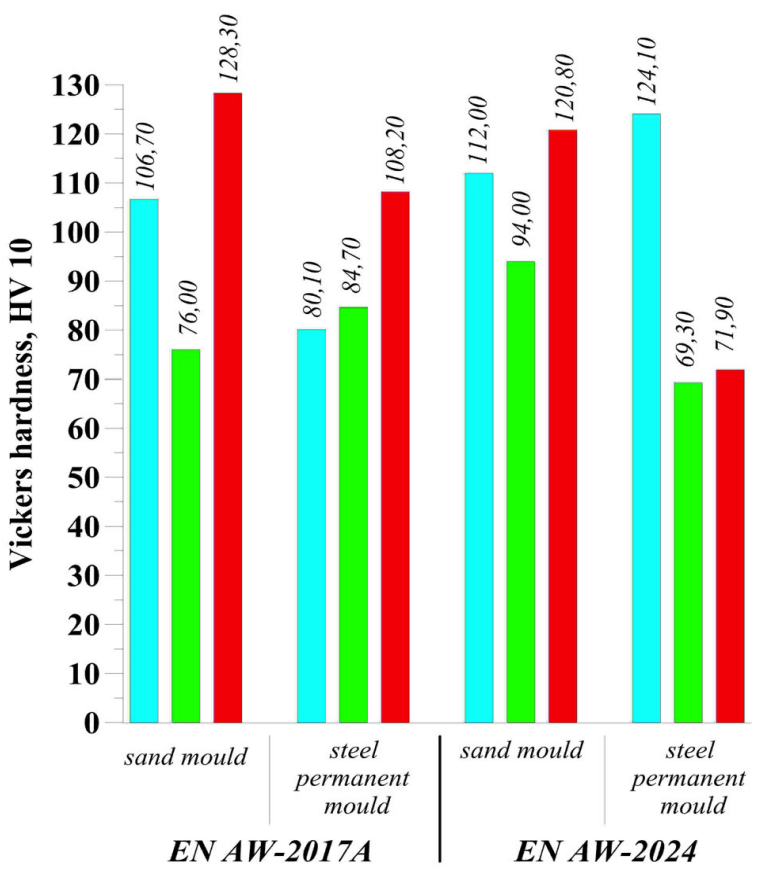

Fig. 3. Vicker hardness of EN AW-2017A and EN AW-2024 specimens after casting and upsetting

en aw-2024 alloy castings produced in sand and steel permanent moulds; cracks occur along the grain boundary on the lateral surface of the specimens,

5. As a result of deformation, the hardness of the castings increases (when compared to their hardness after homogenization); comparing the two tested aluminium alloys, the increase in hardness after the forging process is higher for the sand-mould castings than for permanentmould castings.

\section{Acknowledgement}

Project "The Design and Implementation of an Innovative Low-Waste Metal Forming Technology for High-Strength Light Metal Alloys Used in the Aircraft and Automotive Industry"; No. LIDER/10/0058/L-8/16/NCBR/2017. Total cost of the Project: 1,200,000 PLN.

The project is financed by the National Centre for Research and Development under the 8th edition of the LIDER Programme.

\section{REFERENCES}

1. Zhang Q., Miao C., Dawei Z., Shuai Z. and Jue S. Research on integrated casting and forging process of aluminum automobile wheel. Advances in Mechanical Engineering, 6, 2015, 1-12.

2. Płonka B., Kłyszewski A., Senderski J. and LechGrega M. Application of Al alloys, in the form of cast billet, as stock material for the die forging in automotive industry. Archives of Civil and Mechanical Engineering, 8(2), 2008, 149-156.

3. Kim H.R., Seo M.G. and Bae W.B. A study of the manufacturing of tie-rod ends with casting/forging process. Journal of Materials Processing Technology, 125-126, 2002, 471-476.

4. Wang S.I., Seo M.K., Cho J.R. and Bae W.B. A study on the development of large aluminum flange using the casting/forging process. Journal of Materials Processing Technology, 130-131, 2002, 294-298.

5. Zhou H.T., Xu S.X., Li W.D., Wang S.C. and Peng Y. A study of automobile brake bracket formed by casting-forging integrated forming technology. Materials and Design 67, 2015, 285-292.

6. Standard PN-H-04411.

7. Malas J.C., Venugopal S. and Seshacharyulu T. Effect of microstructural complexity on the hot deformation behavior of aluminum alloy 2024. Materials Science and Engineering: A, 368(1-2), 2004, 41-47.

8. Segal V.M. New hot thermo-mechanical processing of heat treatable aluminum alloys. Journal of Materials Processing Technology, 231, 2016, 50-57.

9. Winiarski G., Gontarz A. and Dziubińska A. The influence of tool geometry on the course of flanges radial extrusion in hollow parts. Archives of Civil and Mechanical Engineering, 17(4), 2017, 986-996.

10. Winiarski G. and Gontarz A. Numerical and experimental study of producing two-step flanges by extrusion with a movable sleeve. Archives of Metallurgy and Materials, 62(2), 2017, 495-499.

11. Różyło P. and Wójcik Ł. Fem and experimental based analysis of the stamping process of aluminum alloy. Advances in Science and Technology Research Journal, 11(3), 2017, 94-101.

12. Gontarz A., Dziubińska A. and Okoń Ł. Determination of friction coefficients at elevated temperatures for some $\mathrm{Al}, \mathrm{Mg}$ and $\mathrm{Ti}$ alloys. Archives of Metallurgy and Materials, 56(2), 2011, 379-384.

13. Bulzak T., Tomczak J. and Pater Z. Forming a lever preform made of aluminium alloy. Metalurgija, 53(4), 2014, 505-508.
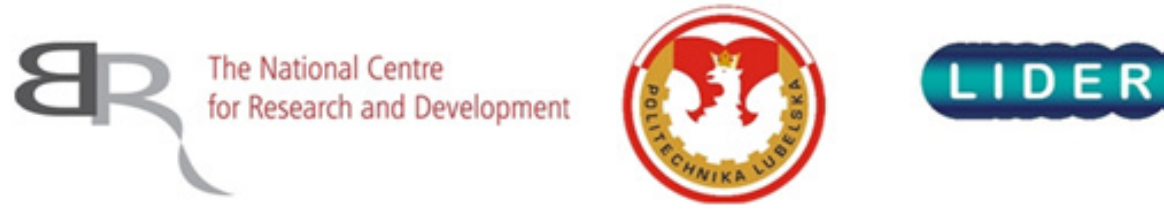